\title{
Laboreal
}

Volume 7 NN$^{\circ} 2$ | 2011

Varia

\section{Exploração nuclear, coordenação dos tempos e dos espaços profissionais}

Explotación nuclear, coordinación de los tiempos y de los espacios profesionales

Exploitation nucléaire, coordination des temps et des espaces professionnels

Nuclear exploitation, coordinating professional timings and spaces

\section{Olivier Guillaume}

\section{CpenEdition}

\section{Journals}

\section{Edição electrónica}

URL: http://journals.openedition.org/laboreal/7698

DOI: $10.4000 /$ laboreal.7698

ISSN: 1646-5237

\section{Editora}

Universidade do Porto

Refêrencia eletrónica

Olivier Guillaume, «Exploração nuclear, coordenação dos tempos e dos espaços profissionais », Laboreal [Online], Volume $7 \mathrm{~N}^{\circ} 2$ | 2011, posto online no dia 01 dezembro 2011, consultado o 10 outubro 2019. URL : http://journals.openedition.org/laboreal/7698; DOI : 10.4000/laboreal.7698

Este documento foi criado de forma automática no dia 10 outubro 2019.

\section{(c) (†) \&)}

Laboreal está licenciado com uma Licença Creative Commons - Atribuição-NãoComercial 4.0 Internacional. 


\title{
Exploração nuclear, coordenação dos tempos e dos espaços profissionais
}

\author{
Explotación nuclear, coordinación de los tiempos y de los espacios profesionales \\ Exploitation nucléaire, coordination des temps et des espaces professionnels \\ Nuclear exploitation, coordinating professional timings and spaces
}

Olivier Guillaume

\section{NOTA DO EDITOR}

Manuscrito recebido em: Abril/2010

Aceite para peritagem : Octubre/2011

0 autor agradece aos correctores anónimos da revista pelas suas observações sobre uma primeira versão do artigo.

\section{De um pedido operacional a uma problematização teórica}

1 Esta contribuição resulta de um estudo levado a cabo para ajudar a pôr em prática novas organizações na exploração de um reactor nuclear. Era-nos pedido para analisar com precisão, e para as melhorar, as relações de coordenação e de cooperação entre as Equipas de Condução de Turno (ECQ - Equipes de Conduites en Quart) [1][2], as Equipas de Condução Extra Turno (ECHQ - Equipes de Conduites Hors-Quart ) e o projecto Tranche En Marche (TEM). As Equipas de Turno asseguram a vigilância e a condução dos reactores em tempo real. As Equipas Extra Turno preparam os dossiers técnicos e os documentos de trabalho das actividades para as equipas de turno. O projecto TEM articula as actividades do conjunto dos ofícios de um CNPE (Centros Nucleares de 
Produção de Electricidade) em funcionamento. Estas equipas e projectos contribuem para a exploração das "unidade» dos CNPE com toda a fiabilidade e segurança. As "tranches ", ou unidades, são um conjunto que agrupa o reactor, a sala das máquinas e o alternador gerador de electricidade. Na altura deste estudo, a análise deveria precisar, analisar e classificar as dificuldades e os factores de sucesso na coordenação e cooperação destas equipas, especificando se os seus diferentes ritmos de trabalho podiam explicar as dificuldades na sua coordenação e cooperação. Enfim, após análise, o estudo deveria propor pistas de actuação para melhorar as relações de coordenação e cooperação.

2 Antes da realização dos estudos empíricos, a análise da literatura mostrou que o estudo das relações de coordenação entre equipas no seio dos serviços de condução e depois entre serviços de condução e serviços de manutenção dos CNPE tinha sido pouco abordado até ao presente. A análise da condução de centrais nucleares tinha-se centrado, até ao momento, nas equipas de turno, nas actividades em sala de comando e nas relações de cooperação no seio destas equipas. F. Chateauraynaud (1997) estudou assim a responsabilidade profissional dos operadores em sala de comandos a partir das actas de atenção e de verificação. G. Jobert (2005) esclarece a queixa de não reconhecimento de operadores que não produzem objectos tangíveis e cujas tarefas os confinam na esfera do trabalho [3]. F. Osty (2002) mostra que a competência do ofício de condutor resulta da aquisição individual e permanente de saberes teóricos complementares das regras e dos documentos prescritos que se tornam colectivos graças às relações de confiança e de intercompreensão no seio da sua comunidade profissional. O. Guilhaume \& J. P. Labarthe (2008) consideram que a cooperação entre membros das equipas de condução por turno assenta em grande parte num sistema de organização " colegial ».

Ora os serviços de condução dos CNPE's não se reduzem às equipas de turno que efectuam a condução e a vigilância das unidades nucleares mas são também compostas pelas equipas de preparação e de engenharia denominadas de "hors-quart» (extra turno). Estas últimas estão encarregadas de preparar as actividades em ligação com os serviços de manutenção, de verificar e completar o planeamento destas actividades e os dossiers das intervenções de ensaio e de manutenção antes de enviar os dossiers destas actividades às equipas de condução de turno para a sua aplicação. As actividades são, ou periódicas, oriundas dos dossiers de intervenções e de ensaios de manutenção, ou fortuitas e oriundas de pedidos de intervenção. Com efeito, as falhas materiais detectadas nas instalações tornam-se pedidos de intervenção a efectuar pelos oficiantes de manutenção e são integradas nos planeamentos gerados pelo projecto TEM. Estas intervenções têm uma incidência essencial na fiabilidade e na segurança da exploração do CNPE. Mal preparadas ou mal efectuadas, as intervenções de manutenção arriscarse-iam a reduzir a produtividade do reactor ou a alterar a sua segurança. A responsabilidade pelas operações mal efectuadas recairia, a seguir, nas equipas de turno e seus dirigentes que deveriam tê-las antecipado e evitado. Devendo a preparação, a programação e a execução das intervenções de manutenção ser efectuadas com precisão, as relações de coordenação entre equipas de preparação e de execução das equipas de condução e dos serviços de manutenção são, portanto, parte essencial da construção da fiabilidade e da segurança das CNPE quando do seu funcionamento normal. 
4 Se as teorias que analisam a fiabilidade e a segurança das organizações de risco não se centram somente na análise dos seus acidentes mas igualmente no seu funcionamento normal, vão buscar vias mais ou menos distanciadas da análise da coordenação concreta dos serviços em exploração.

5 O estudo dos factores organizacionais da fiabilidade arranca com as análises de C. Perrow (1984) considerando que os acidentes são uma consequência directa da complexificação dos sistemas técnicos e do seu alto nível de interdependência. Raros mas ainda assim normais, os acidentes inscrever-se-iam na própria existência dos sistemas. A contrario a escola das Organizações Altamente Fiáveis (HRO) constata que os acidentes, finalmente acontecem bem pouco nestas organizações devido a uma profissionalização dos seus membros, construída graças a um sólido conhecimento técnico e empírico consolidado por uma formação contínua ao longo da carreira. A elevada motivação dos operadores e a fraca rotação do pessoal garantem, por acréscimo, uma continuidade no seu ofício para adquirir um conjunto de saberes-fazer. Enfim, a organização selecciona os mais competentes e os novos recrutas são formados por um padrinho (Laporte, 2001). A profissionalização permite aos operadores tomar as decisões necessárias à resolução de situações urgentes se respeitarem os procedimentos fundamentais que não devem ser nem excessivamente numerosos nem demasiado complexos e rapidamente alterados. O pensamento criador e crítico é também valorizado e recompensado. Os actores são convidados a examinar honestamente os seus erros para os analisar e deles retirar as conclusões que evitarão quaisquer repetições (Westrum, 1987). São, além disso, encorajados a identificar e corrigir o mais rapidamente possível, nas suas tarefas, todas as variações relativamente às regras. Por fim estas organizações encorajam e amplificam os valores do desafio, da variedade, do apoio e do reconhecimento, mais do que os da burocratização e do sancionamento. É preciso acrescentar a importância dada aos exercícios de simulação, uma estrutura organizacional estrita, uma tomada de decisão descentralizada e a importância do treino e da formação (Roberts, 1990, p. 165).

6 A reflexão em torno das regras é fundamental nestas organizações. A exigência de segurança acrescenta-se ao número e ao detalhe das regras formais para antecipar e controlar os incidentes. As organizações formalizam assim novos "cenários" e “procedimentos» para controlar os riscos, obter comportamentos pertinentes e coordenar os indivíduos para que cooperem (Davoudian et al, 1994). Todavia a proliferação de regras pode bloquear os sistemas. R. K. Merton (1965) mostra que a obtenção de um comportamento estandardizado estritamente conforme às regras prescritas arrasta o desenvolvimento de uma atitude ritualista em que as regras aparecem como um fim em si. Os indivíduos renunciam a procurar alternativas às regras definidas mesmo quando as condições de trabalho evoluem. Ao estudar uma central nuclear americana, M. Bourrier (1999) apresenta resultados análogos. Governada por regras formalizadas ao exagero e em que o peso da hierarquia é considerável, a reactividade do conjunto é muito limitada. Os operadores, não dispondo das informações necessárias, não se dirigem senão à hierarquia, recusam mobilizar a própria inteligência para procurar soluções para os problemas encontrados e não trabalham senão sob ordens explícitas. Na sequência dos trabalhos de R. K. Merton, M. Crozier (1964) demonstra que a extensão das regras bloqueia as organizações em círculos viciosos. A rigidez das regras e das tarefas torna difíceis as comunicações entre grupos e com a envolvente. Estas dificuldades são usadas pelos indivíduos e pelos 
grupos para melhorar a sua posição na luta pelo poder no seio da organização, suscitando no interior das direcções a criação de novas regras impessoais. Felizmente as organizações de risco ultrapassam estes bloqueamentos quando aplicam parcimoniosamente as regras em regime normal (Saglio, 2001) [4] ou quando os actores conseguem melhorar as regras formais de "controlo", transformá-las (de Terssac, 1992) articulando-as e integrando uma parte das "suas regras autónomas » (Reynaud, 1989 ; de Terssac, 1992) nas " regras de controlo » (Reynaud, 1989).

Enfim, desde os anos 1990, na sequência de várias achegas académicas [5] e de acidentes major [ $\left.{ }^{6}\right]$ as organizações de risco tentam formalizar as culturas para reforçar a segurança e a capacidade dos actores para gerir os riscos. Os textos INSAG da AIEA (International Nuclear Safety Advisory Groupe de l'Agence Internationale de l'Energie Nucleaire) visam dotar os actores com comportamentos culturais específicos como a atitude interrogativa, a démarche rigorosa e prudente e a comunicação transparente, consideradas como indispensáveis à segurança. No entanto, para certos autores a cultura da segurança tem sido à partida percebida e operacionalizada como procedimentos administrativos e atitudes individuais face à segurança (Pidgeon, 1998). A valorização de uma só cultura de segurança tropeça na realidade: os grupos profissionais tomando atitudes variadas face à segurança segundo o seu nível hierárquico ou não (Harvey et al, 2002). A análise de tal literatura traz à luz um triplo interesse desta contribuição. Centrando-se não apenas nas equipas de turno mas também nas interaç̧ões entre equipas de condução e equipas de manutenção, em primeiro lugar esses desenvolvimentos completarão empiricamente a compreensão da condução de organizações de risco, trazendo também elementos concretos de análise sobre a construção quotidiana da fiabilidade e da segurança. Em segundo lugar a contribuição mostrará que a fiabilidade e a segurança da exploração destas organizações, quando no seu funcionamento normal resultam não apenas das suas capacidades de pôr em prática sistemas de direcção, uma regulação e culturas adequadas, mas também de coordenar temporalidades e espaços profissionais diferenciados, nomeadamente em “segmentos" (Strauss, 1961/1992). A interacção entre as actividades das equipas por turno e extra-turno na condução e as dos serviços de manutenção torna-se de facto difícil devido à separação e segmentação dos espaços profissionais e à dessincronização dos seus tempos de trabalho (Parte I). A fim de reduzir estas disparidades os CNPE tentam unificar os tempos de trabalho através de planos de exploração únicos e depois coordenar os espaços profissionais via dossiers de intervenção (Parte II). Mas os planos podem desorganizar-se em virtude de uma diminuição de recursos, de imprevistos técnicos ou do temor das equipas de condução de gerar incidentes que afectem a segurança. Os planeamentos representam com efeito, os quadros temporais (Grossin, 1996) que se opõem ao meio temporal das actividades de trabalho. Baseada num estudo comparativo entre dois CNPE's a contribuição mostrará que a fiabilidade dos planeamentos e a riqueza dos dossiers de intervenção melhoram quando, os CNPE, graças às aprendizagens organizacionais e colectivas de longo prazo, edificam organizações do trabalho e relações sociais adaptadas que reforçam as actividades de preparação e permitem a cooperação com vista a ajustamentos face aos imprevistos. 


\section{Método de inquérito e de análise}

8 As análises e as respostas às questões de partida foram alcançadas graças a estudos empíricos qualitativos e indutivos levados a cabo no seio dos serviços de condução, dos projectos TEM e dos serviços de manutenção de dois CNPE's (instalações nucleares). As análises comparativas foram conduzidas via entrevistas semi-estruturadas ( $\mathrm{n}=42$ para as duas instalações), por observação de actividades de trabalho ( $\mathrm{n}=12$ para as observações longas) e por análise de documentos internos. As entrevistas duravam uma hora e um turno em média e eram guiadas por uma grelha semi-aberta de uma dúzia de questões, recomposta em função dos interlocutores e dos avanços do estudo. Cerca de metade das entrevistas foi gravada. Algumas foram totalmente transcritas. 0 modelo de análise aqui apresentado não foi estabelecido a priori mas reconstruído a posteriori após a compreensão e o cruzamento dos dados empíricos.

\section{A exploração dos CNPE's : da perturbação dos tempos à sua harmonização}

9 O funcionamento em contínuo dos CNPE's implica que as intervenções e os ensaios de manutenção efectuados nos circuitos técnicos sejam bem preparados para serem compatíveis entre eles e correctamente executados. Enquanto que uma preparação necessitaria que fosse efectuada concertadamente com os serviços de condução e de manutenção, estes últimos agrupando diferentes ofícios como os oficiantes de automação ou os técnico dos ensaios, da mecânica, da caldeiraria, da química... indispensáveis à manutenção e à performance das instalaçãos, os distintos horários de trabalho não o permitem de todo. As equipas por turno da condução asseguram uma rotação contínua de três equipas que se sucedem, das $5 \mathrm{~h} 30$ às $13 \mathrm{~h} 30$, das $13 \mathrm{~h} 30$ às $21 \mathrm{e}$ das $21 \mathrm{~h}$ às $5 \mathrm{~h} 30$ na pilotagem dos reactores enquanto que as equipas de manutenção seguem os horários de uma jornada entre as $8 \mathrm{~h}$ e as $16 \mathrm{~h} 30$ de segunda a quinta-feira [ $\left.{ }^{7}\right]$. As equipas de condução do turno da noite e da manhã (antes das $8 \mathrm{~h}$ ) ou de fim-desemana não podem portanto interagir com as equipas de manutenção a respeito de uma actividade ocorrida durante o seu turno e também não encontrarão resposta às suas questões sobre o planeamento de actividades e os assuntos em estudo analisados no fim-de-semana.
“Temos claramente um problema em Accu RIS. Pediram-nos para fazer um estudo de impacto em Accu RIS. Mas como é que vou buscar esta informação ao fim de semana? Porque ela está na bolsa de fim de semana do pólo de preparação da condução (Operador de turno, instalação $\mathrm{n}^{\circ} 1$ )

Por causa da sucessão das equipas, uma equipa de condução também não tem a certeza de obter as respostas às perguntas em epígrafe nem a programação das actividades de manutenção. As respostas podem ser dirigidas a uma outra equipa de condução.

\footnotetext{
" Uma equipa de turno que começa segunda-feira pôde fazer os seus reparos sobre o planeamento e as actividades no pólo de preparação da condução na segunda-feira anterior. Mas como está em descanso de quarta a segunda (equipa de turno), quando começa na segunda-feira não tem, por isso, a resposta às suas questões. Foi uma outra equipa que as obteve o que lhe provoca inquietações » (Operador de turno, instalação $n^{\circ}$ 1).
} 
11 Não tendo qualquer interesse em que as intervenções de manutenção sejam mal preparadas ou mal efectuadas, os CNPE's criam os projectos TEM e as estruturas de condução extra-turno que geram planeamentos e dossiers de intervenção fiáveis para coordenar os serviços de condução e de manutenção.

\subsection{A coordenação dos tempos através do planeamento}

12 Para coordenar as diferentes temporalidades da manutenção e da condução, os projectos TEM geram planos unívocos que integram os pedidos de intervenções de manutenção fortuitos, previsíveis e reprogramados. Esses planos são verificados e completados pela estrutura de condução extra-turno antes de serem enviados para aplicação, às equipas de turno. Elaborado para duas semanas, o planeamento é afinado e validado quotidianamente para coordenar as actividades e evitar gerar acidentes. Estes instrumentos formalizam, coordenam, medem e dão ritmo aos tempos das actividades de manutenção e de condução. Retomando os trabalhos de P. A. Sorokin (1964), R. Sue (1964) mostra assim que o tempo é uma medida abstracta de coisas concretas. O tempo coordena, mede e dá ritmo às actividades sociais, das quais é o produto (Sue, 1994, p. 22). Mas os planeamentos estão sujeitos ao aleatório, adiamentos de actividades e acções forçadas. São frequentemente perturbados, não podem nem coordenar completamente as actividades nem medi-las nem determinar-lhes o ritmo. Impõem por vezes os seus próprios ritmos e medidas, independentemente dos das actividades reais.

\subsubsection{Planeamento e coordenação perturbada dos tempos}

13 As entrevistas e as observações fervilham com exemplos relatando a reorganização contínua dos planeamentos.

“ há muitas actividades que não são executadas nem para fixar por falta de recursos ou por razões fortuitas. Não temos ainda um planeamento suficientemente forte ...isso levou a que esta tarde, por exemplo, vamos ter novo planeamento e portanto o O. P. C. C. no calor da análise das actividades não tem tempo para analisar tudo e antecipar-se porque o planeamento foi perturbado. E, neste caso, encontra incompatibilidades e incongruências e portanto não dá o acordo para as autorizações de intervenção. Portanto isso perturba de novo o planeamento » (CED equipa de condução por turno, instalação no 1)

14 Antes de mais os planeamentos são repostos em questão em virtude da gestão complexa das peças separadas e da superveniência de incertezas técnicas. Para evitar custos de armazenagem, a falta de reserva de peças separadas julgadas não prioritárias em termos de segurança e de disponibilidade da instalação obriga os serviços a encomendálas no momento da programação da actividade. Mas a peça pode, de vez em quando, ser dada como tendo chegado mas estar fisicamente ausente no momento da realização da actividade, enviada para outro sítio se a actividade é reprogramada diversas vezes ou ainda ter sido devolvida por não obedecer às especificações. Acontecimentos destes obrigam à reprogramação da actividade e à modificação dos planos. Afectando sobretudo a instalação $n^{\circ} 2$ de concepção mais antiga, o imprevisível aleatório das técnicas, tratado com prioridade, obriga igualmente a uma reprogramação do planeamento... 
“ há mais incertezas porque há problemas de manutenção. Era preciso adaptar a manutenção ao envelhecimento da central. Não é normal que não pare de haver avarias de certos materiais » (DSE, instalação no2). entre o estado do planeamento previsto com uma semana de antecedência e o planeamento real da semana, mostra a importância da organização do trabalho e dos recursos afectados à preparação e ao controlo do planeamento. Em ambas as instalações, a taxa de fiabilidade obtém-se na terça-feira da semana seguinte.

Na instalação $\mathrm{n}^{\mathrm{o}} 1$ os efectivos das equipas extra turno são tidos por pouco importantes, nomeadamente no pólo método, encarregado do controlo e do ajustamento quotidiano do planeamento e dos dossiers de intervenções de manutenção.

\begin{abstract}
“A preparação da condução, eles são actualmente dois. Mas para todas as equipas e para todas as unidades, (...) Será que duas pessoas são suficientes para esta actividade? Não, isso torna-se difícil porque além disso há as formações, as férias, os dias de redução do tempo de trabalho Eram precisas três pessoas para as duas unidades » (Director da estrutura de condução extra turno, instalação $n^{\circ}$ 1).
\end{abstract}

17 Os efectivos reduzidos levam os membros do pólo a consagrar o essencial do seu tempo ao controlo dos dossiers de intervenção para responder a objectivos quantitativos que lhe são impostos pelo projecto TEM. Na verdade, determinados responsáveis pelos ofícios de manutenção duvidam da capacidade do pólo para efectuar uma análise a fundo dos documentos dos dossiers de intervenção $\left.{ }^{[8}\right]$ e dos planeamentos para detectar incongruências e anomalias.

“...é necessário, num dado momento, fazer uma análise do risco das actividades que deve ser transversal. Vejamos, eu desenvolvo uma determinada actividade e ao mesmo tempo os oficiantes dos automatismos intervêm no controlo do comando. Deverá isso perturbar a nossa actividade ou devemos bloquear as actividades dos anteriores? Normalmente são os métodos da condução que devem fazer isso. Eles não têm talvez suficientes recursos ou competências. São poucos, acho eu, para este género de actividade dada a complexidade das actividades. Eles funcionam em interface com a condução, a segurança, mas não com as outras especialidades. " (Encarregado dos assuntos de manutenção, instalação $\mathrm{n}^{\circ}$ 1).

Desconfiados, os membros das equipas de turno podem reforçar a vigilância dos dossiers de intervenção e dos planeamentos que lhes chegam, detectar uma lacuna ou uma incongruência e recusar a intervenção que ficará para reprogramar. Temendo deixar realizar uma actividade mal programada ou mal preparada que possa gerar eventos de que teriam de assumir a responsabilidade, eles relatam as intervenções para não assumir qualquer risco.

\footnotetext{
“(...) isso depende da antiguidade do encarregado dos trabalhos e das competências. O jovem, eles vão chegar rapidamente a bloqueá-lo, vão pôrlhe questões, ele não conseguirá responder. É de tal forma complexo, com as especificações, o funcionamento...

- Mas qual é o interesse deles na condução?
} 


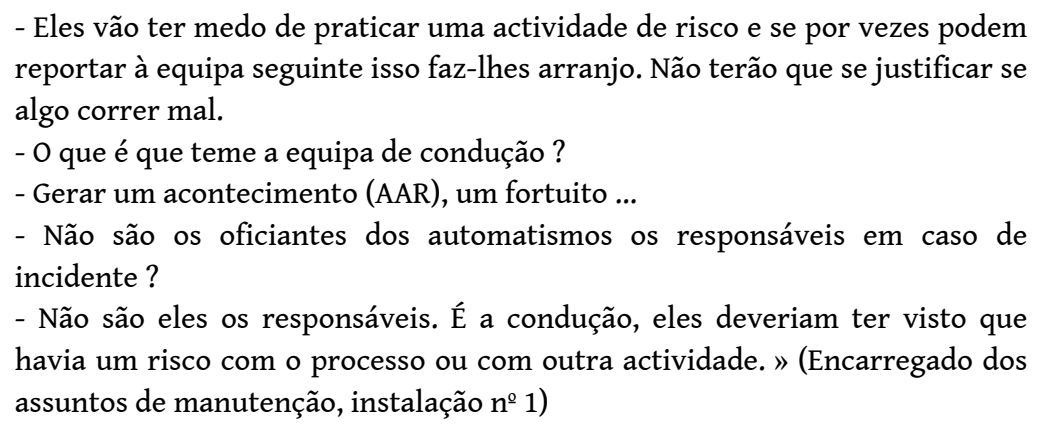

O relato de actividades, em cima do acontecimento, desorganiza o planeamento e gera frustração nas equipas de manutenção que em retorno poderão querer "forçar a actuação » colocando as actividades junto da condução mesmo quando elas não tenham sido programadas. Confrontado com um número elevado de operações de manutenção a efectuar, o serviço de manutenção poderá “ fazer um forcing " a fim de inscrever uma nova intervenção na Preparação Urgente (P. U.), quer dizer para levar a cabo o mais rapidamente possível com uma preparação limitada. Ora as P. U.'s desorganizam um pouco mais o planeamento e retiram fiabilidade à intervenção se a preparação é mal efectuada. Para as fazer aceitar, as equipas de manutenção fazem apelo à solidariedade profissional das equipas de turno, à sua “dívida" moral quando tenham podido anteriormente recusar uma intervenção de manutenção ou à ameaça de não intervir com um material ou uma actividade que a condução solicitar.

“... duma penada só tens o chefe das auto(mações), ele vai dizer " eu bem que meteria um rapaz, há um problema que dura já há muito tempo. Olha, vou pô-lo aí... » (...). o tipo quer intervir e isso não está no planeamento e se não está no planeamento não há regra mas ele quer fazê-lo. Portanto é preciso fazer um P. U.. Tu vais ver o operador encarregado da segurança da instalação...:" Será que tu podes fazer um PU para que aquele rapaz vá trabalhar num problema que data de há uma semana e que não está no planeamento...

Nós : "Não está no planeamento "

O chefe da automação lembra " na condução está a chatear-vos...tanto pior, não interviremos no vosso material. » (Operador de condução, instalação no 1).

20 Assim, em virtude da escassez de recursos afectados à preparação da condução, o seguimento e a análise quotidiana dos planeamentos da instalação $\mathrm{n}^{\mathrm{o}} 1$ são parcial e implicitamente relatados por um CED de turno já mobilizado numa extensão considerável das suas actividades. A sua análise prospectiva do planeamento fica pelo parcelar e pode deixar passar anomalias.

“Nós deveríamos estar lá para trabalhar nos planeamentos S+1 enquanto que

lá estão em tempo real, desenrascamos as coisas tu podes facilitar-me isto e aquilo » (CED, instalação nọ).

21 Ponto de entrada permanente das informações que transitam entre os serviços de manutenção, os de condução e o projecto TEM, o CED da instalação $\mathrm{n}^{\mathrm{o}} 1$ deve interceptar, centralizar, reafectar as informações e gerir uma grande parte dos problemas que surgem nas unidades. Chega rapidamente à saturação e perde informações, embora úteis para a manutenção. 
“De noite, justifico-me quanto ao avanço dos trabalhos. Digo quando há coisas desfasadas ou a reagrupar. Digo por que o fiz ou por que não o fiz. 0 CED de turno deve fornecer informação ao encarregado de instruções das duas unidades ... mas metade perde-se mas como eles são da tarde devem comunicar à equipa da noite as informações para eles prepararem ou não prepararem os regimes. E como há sempre perdas de informação e logo de manhã há as prioridades da véspera e as equipas (de manutenção) chegam na manhã seguinte: Ah bem eu não estou ao corrente não há regime » (Encarregado dos assuntos de manutenção, instalação no 1 ). linear, unívoco e prescrito oposto ao tempo real das actividades profissionais constituído por acelerações, urgências, e paragens. O tempo real é um tempo qualitativo englobando múltiplas actividades que escapam à medida prescrita.

\subsubsection{A perturbação dos planeamentos : quadro temporal versus meio temporal}

O planeamento e a sua fiabilidade aparecem como indicadores lacunares para medir a realidade do trabalho das equipas de turno porque às sucessivas actividades programadas com os tempos de realização se acrescenta múltiplos aleatórios cujo tempo de resolução é opaco.

O aleatório mas pouco importante e não afectando a segurança é assim gerado em “ tempo mascarado " graças ao profissionalismo das equipas de condução de turno que não alteram o planeamento que se supõe representar o seu trabalho.

\footnotetext{
“ O que acresce é o fortuito. Isso pode perturbar o planeamento. Mas acrescenta uma carga de trabalho horrível. Isso não pode ser tomado em conta. É trabalho mascarado. Não há indicadores do fortuito.» (CED, instalação $n^{\circ}$ 2).
}

Desconhecido e imprevisto o aleatório não pode ser prescrito e controlado do exterior das equipas. É tanto menos referido, pelas equipas de condução de turno, aos prescritores dos tempos quanto mais lhes permite trabalhar sem obedecer à documentação e planeamentos prescritos. Concedendo um espaço de autonomia, o aleatório representa a possibilidade de incrementar o profissionalismo adquirindo novos conhecimentos e saber-fazer porque se trata de situações inéditas pouco ou nada enquadradas pelos procedimentos.

“(...) a gestão do aleatório é verdadeiramente interessante porque releva da técnica e é para isso que lá se está. Mas as gentes do planeamento não se apercebem (disso). » (CED, instalação $\mathrm{n}^{\mathrm{o}} 2$ ).

Só o aleatório avaliado como importante e/ou com impacto na segurança é feito subir ao projecto TEM pelas equipas de turno para tornar colectivo o seu tratamento e partilhar as responsabilidades em caso de génese de eventos imprevistos.

\footnotetext{
"O aleatório nem sempre sobe ao "pack" TEM. O fortuito gere-se antes. Fazse uma análise de primeiro nível (...) isso depende da importância do aleatório. Se é pouco importante gere-se em directo não chamamos o "pack" TEM. Mas se implica segurança chamamo-los. Mas muito do aleatório toma muito tempo. Gerimo-lo entre nós, felizmente. Mas eles não vêem tudo isto... » (CED, instalação $\mathrm{n}^{\circ}$ 2)
} 
O tempo programado do planeamento não é, portanto, uma medida exaustiva do trabalho real das equipas de turno nem uma medida eficiente do seu trabalho real. Sequencial, o planeamento enuncia actividade por actividade com uma duração de realização prevista e estável enquanto o trabalho das equipas de turno é constituído por múltiplas actividades entrecruzadas, pontuadas por acelerações e urgências e seguidas do repouso indispensável ao domínio da segurança. O tempo prescrito do planeamento encadeia sequências de actividades únicas com ritmos previstos no seio de intervalos definidos, enquanto o tempo de trabalho real das equipas de turno é constituído por actividades concomitantes e pontuado por variações bruscas dos ritmos. O aleatório obriga assim as equipas de condução de turno a realizar simultaneamente múltiplas actividades a um ritmo trepidante durante um lapso de tempo muito curto pontuado por bruscas variações dos ritmos.

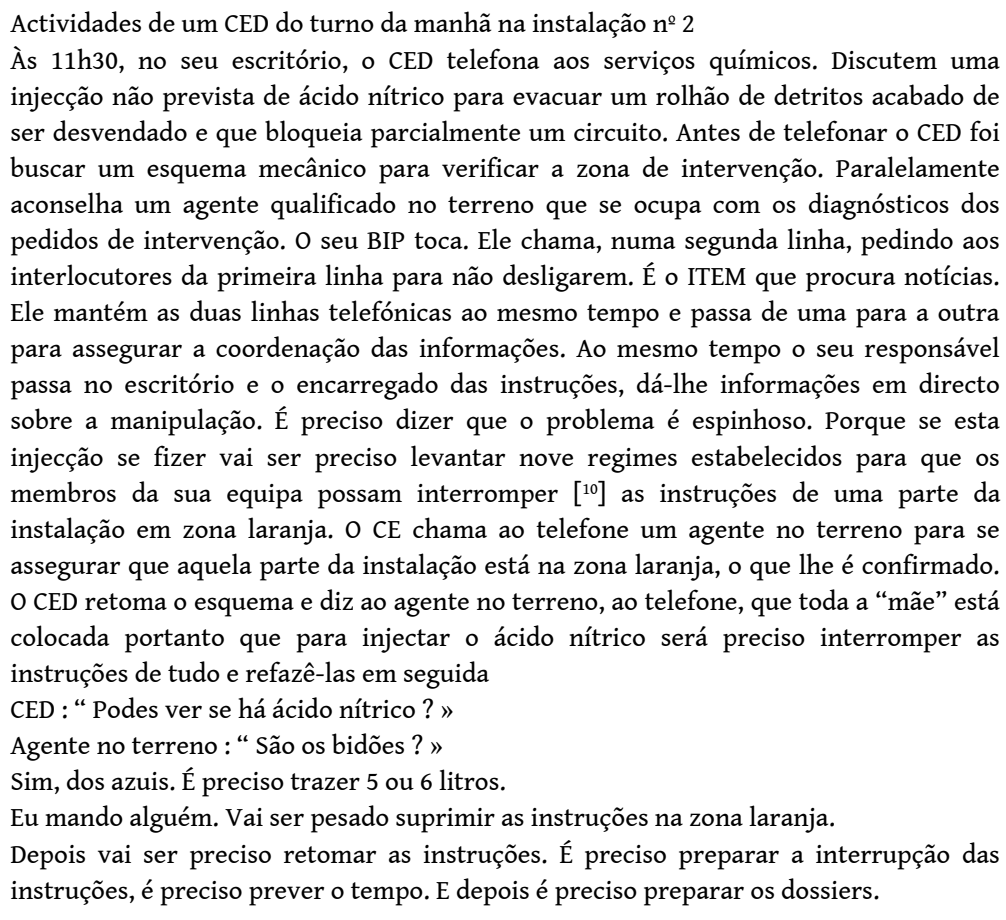

Estes momentos intensos em que numerosas actividades se entrecruzam obrigando o CED a fornecer numerosas informações tentando simultaneamente resolver dificuldades e aleatórios diversos não duram, felizmente, grande tempo. E mesmo que estes momentos se reproduzam várias vezes durante um turno, este é também constituído por longos espaços de tempos calmos com pouca actividade, durante os quais os indivíduos consultam os dossiers, esticando as pernas ao dar uns passos na sala de comando ou ouvem a rádio e discutem. Não se trata de tempo inactivo mas de uma sequência de um regime temporal mais vasto em que as equipas aproveitam os momentos vagos para descontrair a fim de enfrentar uma nova avalanche de variações aleatórias. As variações dos ritmos de trabalho e dos tempos vagos fazem por conseguinte parte da gestão colectiva da fiabilidade.

Por isso a superveniência constante e imprevisível do aleatório a controlar induz as equipas de turno a polarizarem-se numa temporalidade do presente, do imediato. Para 
eles trata-se de esperar a vaga do aleatório mas reservando recursos físicos e cognitivos para os enquadrar. 0 tempo vivenciado pelas equipas de turno reduz-se portanto ao seu turno e mais precisamente ao instante presente desse turno. Integrados num regime do presente, da urgência e da acção, os CED's sofrem então reais dificuldades para se projectarem no futuro e dizem não reler os planeamentos que virão.

“Normalmente deveria trabalhar-se na preparação. É uma abstraç̧ão ... prefiro permanecer na acção. » (CED, instalação nº 2)

Os planeamentos são quadros temporais (Grossin, 1996). Fornecendo uma imagem do tempo, ordenam, hierarquizam e medem as tarefas num tempo linear. Rígido, imposto e restrito, o quadro temporal é fechado, regular e construído sobre medidas. Encerra o tempo de uma substância - aqui o trabalho real - que se descobre em exercício. À noção de quadro temporal pode opor-se a de meio temporal (Grossin, op. cit.). Maleável, livre e extenso o meio temporal é aberto, modificável e sem relações estreitas com uma ordem cronológica. Engloba tempos reais e múltiplos. Os meios temporais das equipas de condução por turno englobam os tempos reais induzidos pelo aleatório do trabalho real. Estes últimos induzem um tempo ecológico (Evans Pritchard, 1934/1964, p. 118) que reflecte a relação dos homens com o seu meio de trabalho. Designado por tempo objecto por R. Sue (1994, p. 96) produto das actividades sociais, aqui de trabalho, coordena essas actividades.

Reflectido pelos planeamentos, o quadro temporal que é uma medida regular e homogénea - põe problemas às equipas de condução de turno porque se aplica sobre o seu tempo ecológico de trabalho, de facto descontínuo, irregular e heterogéneo. E longe de se justapor e de se interpenetrar, quadros temporais e meios temporais são concorrenciais numa relação dialéctica (Grossin, pp. 34 \& 39) que leva à reconfiguração dos planeamentos. Consubstancial às actividades de trabalho, a perda de fiabilidade dos planeamentos pode mesmo assim ser limitada como no-lo ensinam as análises levadas a cabo na instalação $\mathrm{n}^{\circ} 2$. Mau grado as suas quatro unidades mais antigas, esta instalação apresenta taxas de fiabilidade dos planeamentos bem superiores em virtude de um número de preparadores mais importante e da criação da função de engenheiros TEM (ITEM) que recentram o controlo e o seguimento dos planeamentos.

\subsection{A fiabilização do planeamento : da coordenação técnica à cooperação}

A taxa de fiabilidade bem superior da instalação $\mathrm{n}^{\circ} 2$ resulta antes de tudo de uma preparação reforçada. A estrutura extra turno da condução engloba quatro preparadores em "tempo diferido " a fim de elaborar os dossiers de intervenção que aparecem após mais de duas semanas e seis preparadores “em tempo real» para elaborar os dossiers de intervenção que surgem antes das duas semanas. Os engenheiros TEM (ITEM's) ditos “ em tempo real », especificidade da instalação e em número de três, trabalham respectivamente no planeamento das actividades previstas para os próximos 15 dias, no planeamento das actividades previstas para os próximos 7 dias e no planeamento da semana em curso. Esta repartição das actividades permite a cada um coordenar a realização das actividades que preparou desde há 15 dias para melhor as apreender e ser bem sucedido na execução. Quando não estão em reunião os ITEM's verificam constantemente, nos planeamentos, a pertinência das actividades, a 
sua redacção, as suas compatibilidades e a pertinência dos serviços que as devem levar a cabo. Este controlo começa todos os dias de manhã cedo entre o chefe de projecto TEM e o ITEM e prossegue ao longo de todo o dia. Assim, os preparadores das estruturas de condução extra turno podem centrar-se inteiramente na qualidade (precisão, completamento ...) dos documentos de intervenção fornecidos pelos preparadores do ofício que deverá realizar a intervenção. Os encarregados das consignações dão instruções e os membros das equipas de condução de turno dessa instalação sentem então uma confiança certa na qualidade da preparação dos dossiers sabendo que foram múltiplos a preparação e o controlo dos mesmos. Os seus controlos e as suas apreensões diminuem tanto, quanto os seus controlos e adiamentos de actividade.

Espontaneamente os correspondentes dos ofícios de manutenção vêm ver o ITEM para discutir actividades ou dificuldades com as quais se confrontaram ou então os CED telefonam-lhes por razões análogas. Ponto de convergência e de entrada das informações necessárias à execução das actividades previstas o ITEM “ em tempo real » pesquisa e afina as informações técnicas antes de as redistribuir às pessoas adequadas para facilitar a realização das actividades previstas. A sua posição central contribui para incrementar a fiabilidade do planeamento e evita ao mesmo tempo transferir as actividades de centralização e de análise dos planeamentos a um CED de turno, já muito ocupado.

34 Tal como nos planeamentos cuja função era coordenar os tempos de trabalho dos ofícios dos CNPE's, os dossiers que acompanham as intervenções de manutenção transitam entre serviços para coordenar espaços de trabalho separados. Ora estes documentos mantêm-se lacunares quando os recursos afectados à sua redacção e ao seu controlo são por demais limitados e quando encontros físicos inexistentes não permitem o seu enriquecimento.

\section{A exploração dos CNPE's : da segmentação dos espaços profissionais à sua coordenação}

35 Tal como nos planeamentos de tempo, os dossiers de intervenção têm por função coordenar os espaços profissionais.

\subsection{Espaços separados e dossiers de intervenção}

No seio dos CNPE's os espaços profissionais são frequentemente separados uns dos outros e estanques. Os serviços de manutenção situam-se em edifícios independentes dos da condução, dissociada entre a sua direcção reagrupada com as estruturas extra turno num edifício e as equipas de turno situadas na sala de comando a 19 metros num outro edifício independente e próximo do reactor. A separação física dos ofícios e dos serviços também não facilita uma preparação e uma programação conjunta das intervenções de manutenção.

Para colmatar esta separação, a coordenação dos espaços profissionais é assegurada por dossiers de intervenção. Definida como " o agenciamento das partes de um todo segundo um plano lógico, para um fim determinado ", a coordenação do trabalho resulta da aplicação, pelos operadores, de um conjunto de regras para relacionar as tarefas que lhes são atribuídas (de Terssac \& Lompé, 1994, citados por Barthe \& Quéinnec, 1999, p. 672). 
Assim, quando um pedido de intervenção de manutenção é aceite, o encarregado dos assuntos do ofício de manutenção afecta-o a um preparador que elabora um dossier englobando diversos documentos com vista à intervenção. Em paralelo o encarregado prepara os pedidos de regime de instrução e fornece o conjunto à preparação do serviço de condução. $\mathrm{Na}$ instalação $\mathrm{n}^{\mathrm{Q}} 1$, o pólo preparação da condução verifica e completa os documentos e transmite os dossiers às equipas de turno no fim-de-semana para inspecção e anotações. Estas últimas são retransmitidas graças a "fichas de ligação " que transitam até aos planificadores para modificação, se necessária, dos planeamentos. $O$ dossier retorna a seguir ao serviço de manutenção e é atribuído à equipa de intervenção no momento de realização da actividade. Informando os indivíduos sobre as intervenções previstas e melhoradas por todos para obter o seu assentimento, os documentos servem para coordenar os espaços de condução e de manutenção.

Por isso, na instalação no 1 os documentos mantêm-se ainda lacunares. A descrição das actividades a realizar é por vezes considerada como (apenas) alusiva pelas equipas de turno: (...). Frequentemente tem-se uma explicação sucinta do que eles vão fazer e uma proposta de bula de instruções. Frequentemente colocam-se questões sobre o que eles vão fazer e de súbito isso pode mudar a bula em função do que eles vão fazer. Os pedidos de regime são frequentemente demasiado light e não se sabe bem o que devem fazer. " (Operador, equipa de turno). o pólo preparação da condução sofrerá dificuldades para verificar a bula de instruções proposta pelos oficiantes da manutenção ou para efectuar a sua : " 0 mais difícil para a estrutura extra turno da condução é a aplicação da bula de instruções porque nem sempre se sabe o que quer mesmo fazer porque a intervenção nem sempre está bem informada. " (Manager da estrutura extra turno da condução). As análises de risco não são anexadas senão para as actividades realmente de risco mas ausentes nas actividades mais anódinas: "As análises de risco é raro tê-las. Mas há quando se trata de actividades de verdadeiro risco. 0 facto de não as ter pode pôr problemas quando se colocam questões. Não se tem interlocutores quando se colocam questões. » (Operador, equipa de turno, instalação $\mathrm{n}^{\circ}$ 1).

Para além da estreiteza de recursos atribuída aos pólos de preparação, as lacunas dos dossiers de intervenção parecem resultar igualmente da dificuldade dos membros das equipas de turno e extra turno da condução e dos serviços de manutenção em se encontrarem para confrontar as suas análises e pontos de vista. Tradicionalmente em certos CNPE's as equipas extra turno da condução servem também para dar emprego aos operadores de condução de turno que já não podem aguentar o tempo de trabalho por turnos ou que não conseguem conservar o seu lugar nesse meio. Nessa configuração eles integram as equipas extra turno não por que o desejem mas por quererem sair das equipas de turno ou por terem tido que sair delas. As estruturas extra turno existem tanto pela sua utilidade para a performance global como por razões sociais.

$$
\begin{aligned}
& \text { “... mas há um grande problema. A condução por turnos tinha uma má } \\
& \text { tendência para transferir os operadores de quem queria desembaraçar-se, } \\
& \text { gente não essencial às equipas de turno ou gente com problemas de saúde. } \\
& \text { Maldosamente dizia-se que se punham de lado os braços partidos... " (Chefe } \\
& \text { de exploração, instalação } \mathrm{n}^{\circ} \text { 2) }
\end{aligned}
$$

Os membros das equipas extra turno separam-se pois, progressivamente das equipas de turno que se encerram nelas próprias e imprimem uma grande solidariedade entre os seus membros. 
“ O trabalho de condução é já estar numa equipa. Eu vejo as equipas como microestruturas quase familiares entre amigos em que quando se está na merda se arranja ajuda de um irmão mais velho, um irmão mais pequeno a que se pode dar uma mão, um tipo tecnicamente forte, os tipos um bocado mais afinados na informática, é um pequeno grupo, um pequeno núcleo duro que faz com que se saiba sair-se bem. » (Operador de condução, instalação no 1)

41 O ofício da condução separa-se assim em várias partes. Estudando as profissões médicas hospitalares, A. Strauss (1961/1992, pp. 70 a 86) mostra que numa profissão várias características se distinguem criando outros tantos "segmentos ». 1) o sentido de missão e os valores associados podem ser distintos entre membros de uma profissão. No seio das profissões médicas, a importância consagrada ao diagnóstico, à pesquisa ou à intervenção podem variar entre os indivíduos, criando especialidades e grupos distintos. 2) As actividades de trabalho, a sua definição e a sua organização podem ser diferentes. 3) As metodologias e as técnicas podem também variar. 4) Os membros dos segmentos perseguem interesses profissionais diferentes. De entre os médicos, alguns vão favorecer unicamente a pesquisa teórica e académica enquanto outros vão tentar profissionalizar os saberes teóricos para melhorar as suas intervenções. As profissões e as organizações são uma amálgama de “segmentos » resultante de actividades, de metodologias, de valores, de sentidos de missão ... distintos. Cada um dos segmentos tenta alargar o seu território, assegurar a hegemonia das suas concepções e dos seus métodos. As tensões entre segmentos são reforçadas pelos laços de solidariedade e de exclusividades que se tecem entre os seus membros. E quanto mais reduzidos são os territórios dos segmentos mais se exprimem as relações de solidariedade entre os seus membros e mais vivas são as tensões com os outros segmentos.

Com este modelo teórico, a condução aparece como uma profissão que se decompõe em “ segmentos ». Desvela os “ segmentos " “ equipas de turno » e “ equipas extra turno » desdobrando-se noutros tantos segmentos em torno das funções de operador, agente no terreno, ... Cada um destes “ segmentos » apresenta actividades, métodos, técnicas e interesses distintos podendo criarem-se tensões ligadas à diversidade das práticas, dos interesses e dos laços de solidariedade. Logo quando o ajustamento e enriquecimento dos documentos de intervenção e de planeamento necessitaria de permutas e de uma concertação graças a reuniões físicas entre as equipas extra-turno e de turno da condução, nenhum encontro físico existe entre os membros das estruturas fora de turno e de turno na instalação n⿳0 1 . Os segundos estão acantonados na sala de comando e os primeiros nos escritórios funcionais num edifício à parte. Todas as trocas de informação se fazem através de documentos em papel ou suporte informático.

“ O pessoal do pólo preparação da condução, não se vê. Nunca se vê. Dá um bocado de pena, é um bocado difícil manter relações com gente que nunca se vê. Mas actualmente a constatação está feita. Não nos falamos. Conhecemonos porque são os antigos da condução de turno mas é raro sabê-lo. » (Operador, equipa de turno, instalação $n^{\circ}$ 1)

Estabelece-se uma quase fronteira entre estas equipas porque uma fronteira comporta uma finalidade social fundamental (Simmel, 1903/1999, pp. 605 \& 607) : ela delimita uma entidade social, fecha-a sobre si própria e reforça a instalação entre os seus membros. A fronteira reforça a instalação dos membros das equipas de turno a fim de enfrentar o aleatório e os incidentes mas aumenta a distância para os membros extra 
turno que poderiam já hesitar em querer confrontar as suas análises com as das equipas de turno no caso de limitações técnicas. Ora na instalação $\mathrm{n}^{\mathrm{0}} 2$, conscientes da insuficiência de uma só coordenação através de documentos, os actores articulam os espaços da condução e da manutenção graças à cooperação constante entre indivíduos cujas competências técnicas e relacionais permitem encontros, críticas e permutas.

\subsection{Dos espaços fragmentados à cooperação profissional}

Rompendo com um hábito comum a diversas instalações, o serviço de condução do CNPE $n^{\circ} 2$ deixou de afectar, com prioridade, às estruturas extra turno da condução, os indivíduos que já não podiam ou não queriam ficar nas equipas de turno. As " escolhas por defeito " não permitiam recrutar indivíduos com competências robustas que a partir de então não se confrontavam com os membros das equipas de turno para não pôr a nu algumas das suas fraquezas.

“Antes havia gente que estava farta do 3X8. Pegava-se nessa gente e punhase nos projectos (TEM ou paragem da unidade). De repente os projectos ficavam mancos... De repente quando se propunha aos melhores serem destacados não era muito valorizado. Era um pouco tipo hospital. Vou substituir alguém que estava... em todo o caso não era valorizado.» (Manager, Serviço de condução, instalação no 2).

O serviço de condução da instalação no 2 inverteu a lógica de recrutamento atraindo os melhores das equipas de turno para o seio das equipas extra turno. É recomendado, de aí em diante, às pessoas que desejam subir os degraus hierárquicos do seu ofício que procedam a um destacamento de alguns anos num posto de uma estrutura extra turno do projecto TEM. Os operadores que desejem tornar-se encarregados das instruções devem ter sido preparadores dos dossiers de intervenção e os jovens engenheiros ou CED que querem tornar-se CE devem tornar-se ITEM durante vários anos.

\footnotetext{
“Agora levam-se os melhores para os projectos dos postos de ITEM's. E é o mesmo para os preparadores da condução.

- E como se faz para atrair os melhores?

- (...) A condução, para os operadores, para ir para os postos de chefe de exploração delegado ou de DSE é preciso que seja destacado para os projectos de modo notório. De facto é um fenómeno tipo bola de neve. Agora só existe o embaraço da escolha. Idem para os CE, impuseram-se percursos cruzados. $\mathrm{O}$ CE deve ter feito destacamentos para a manutenção e agora o mínimo de percurso cruzado é ter sido ITEM.» (Manager, Serviço de condução, Instalação nº 2).
}

A escolha dos Manager incide igualmente na complementaridade dos perfis dos ITEM's de tempo real. A variedade dos perfis (um antigo Engenheiro da Segurança; um antigo CED de turno e um jovem engenheiro) favorece uma diversidade de interpretações, uma confrontação e um agregado de informações que concorrem para a fiabilização dos seus julgamentos e decisões. Situando-se, todos três num mesmo espaço com escritórios próximos, falam-se constantemente, dialogam e trocam informações para fiabilizar os seus diagnósticos e acções. O CED de turno mantém assim um muito bom conhecimento técnico do processo; o jovem engenheiro tem uma capacidade de abstracção e negociação e o antigo engenheiro da Segurança tem um bom conhecimento das regras técnicas da exploração. A decisão de seleccionar as pessoas que demonstraram as suas 
competências e capacidades de aprendizagem dispondo também de especializações complementares facilita o ajustamento em tempo real do planeamento e a resolução de problemas técnicos. Os ITEM's não têm de facto quaisquer reticências a entabular um diálogo técnico com os seus interlocutores dos ofícios de manutenção ou das equipas de turno, para compreender a natureza do problema, as suas consequências, ou para propor aos seus interlocutores soluções para os resolver. Seguros do seu potencial técnico ou podendo apoiar-se nos colegas, entram facilmente num jogo de cooperação para ultrapassar as tensões entre ofícios ou entre segmentos desses ofícios. Para A. Strauss (op. cit., p. 88) os segmentos divergentes de uma profissão põem-se de acordo graças a um processo de negociação que assenta no dar e receber da diplomacia ou da negociação. Se esta é facilitada, na instalação $\mathrm{n}^{\circ} 2$, pelas competências técnicas dos membros das equipas extra turno fazendo-as legitimar junto dos representantes dos ofícios de manutenção e das equipas de condução de turno, torna-se efectiva através de comunicações explícitas, de encontros simultâneos e da permuta de recursos facilitados pela constituição de um palco TEM. Ocupando o rés-do-chão de um edifício, este palco engloba as estruturas extra turno da condução compostas pelos preparadores e pelos ITEM's em tempo real e diferido, pelos planificadores que recompõem em permanência o planeamento das intervenções, pelos representantes dos ofícios dos principais serviços de manutenção (Máquinas Estáticas e Canalizações, Automação, Química ...) e pelo chefe do projecto TEM. Recreando em modelo reduzido uma articulação fluida entre os espaços da condução, da manutenção e da planificação, o palco permite a centralização das informações pelos correspondentes dos ofícios da manutenção e dos ITEM's. Enfim, a proximidade dos gabinetes no seio de um mesmo espaço aberto favorece as interacções e as constantes permutas de informação com vista a resolver as dificuldades técnicas e ajustar os planeamentos via negociações directas. Os correspondentes dos ofícios do palco vêm espontaneamente ao gabinete dos engenheiros TEM para discutir os bloqueamentos das actividades ou as dificuldades com as quais são confrontados.

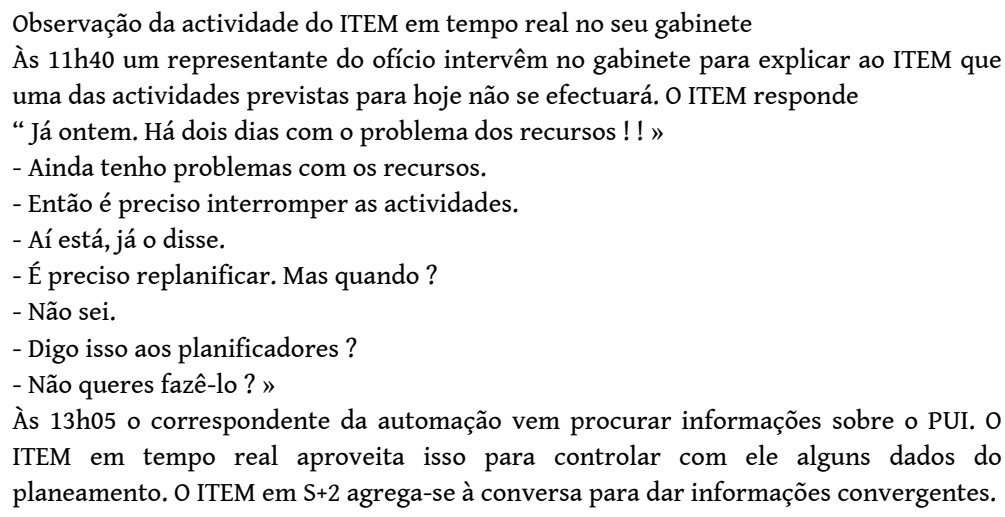

Restringindo os espaços, o palco TEM concentra as informações, permite interceptar as pertinentes e favorece as cooperações. O conceito de cooperação parece mais pertinente que o de negociação para caracterizar as relações sociais no seio deste palco. Com efeito a negociação implica uma simultaneidade na permuta e uma equivalência entre os bens permutados para construir acordos entre indivíduos. Enquanto que, quando das relações de cooperação, os protagonistas não determinam a priori nem a 
natureza nem a extensão dos recursos a pedir aos parceiros nem os momentos exactos da sua colocação em comum, visto que eles se desvendam no decurso da aç̧ão. Também não se trata de uma troca mercantil implicando que os parceiros tenham calculado a priori a equivalência de bens simultaneamente permutados. A cooperação clarifica-se mais pelo modelo de dar/retribuir (Alter, 2009), permuta social encerrada em regras que são a obrigação de dar, receber, e retribuir. 1) A doação confere prestígio, honra, glória e às vezes autoridade ao doador. É uma parte do espírito, da alma do quem dá (Mauss, 1950/2004, pp.160-161). 2) Recusar a doação significa eventualmente ser banido da sociedade, da comunidade ou desencadear hostilidades. Aceitar a doação é aceitar uma parte da essência espiritual da alma do doador e endividar-se face ao doador (Mauss, op.cit., p.161). 3) A doação é um princípio de reciprocidade significando que é preciso retribuir com equidade mais tarde ou mais cedo. Mas esta retribuição não está ligada a nenhuma condição temporal, de quantidade ou de qualidade. A esperança de reciprocidade é indefinida. E a doação é um acto voluntário e imprescritível. A resolução dos problemas em directo e o bloqueamento das actividades no palco TEM não resulta de uma negociação em que recursos equivalentes se permutam mas uma doação a outrem, em tempo real, de informações e conhecimentos técnicos e organizacionais sobre o desenrolar das actividades e dificuldades encontradas. Em retorno, aquele que recebeu informações úteis para a sua actividade retribuirá com informações sem lhes ter calculado a equivalência e sem ser obrigado a retribuir.

Enfim, a eficácia da exploração é, na instalação $\mathrm{n}^{\circ} 2$, reforçada pela criação de espaços de deliberação. Reuniões específicas competem aos correspondentes dos ofícios do palco TEM envolvidos no aleatório, ao ITEM em tempo real da semana e ao chefe do projecto TEM. Este último desempenha um papel de animador e de facilitador na compreensão e na resolução da dificuldade fazendo com que lhe expliquem o problema, permitindo a todos exprimirem-se sobre as origens e as consequências do problema. Tenta agregar os conhecimentos oriundos de horizontes profissionais diferentes para elaborar um diagnóstico e uma estratégia de acção que obtenha consenso entre os diferentes actores presentes. A compreensão e a resolução de problemas técnicos complexos ou inéditos não resulta de uma imposição hierárquica de uma solução prévia. Requerem benevolência, permuta e agregação dos conhecimentos de cada um para elaborar consensos e evitar restringir a compreensão da origem do problema e das suas consequências. Estas reuniões eficazes aparentam-se ao conceito de "espaços de sentido » evocado por Z. Laidi (1998, pp. 9 \& 21) : trata-se de espaços deliberativos no seio dos quais intervêm actores para produzir “ preferências colectivas " antes de os converter em performances políticas para atingir um certo número de objectivos. Respondendo simultaneamente às condições de deliberação, de enunciação e de performance (Laidi, op. cit., p. 36), o “ espaço de sentido » cria um conjunto de valores e de interesses comuns que unificam um colectivo de actores via "imagens partilhadas " (Hermet, 1998, p.47). Estas imagens produzem preferências que facilitam uma projecção colectiva com fins identitários e estratégicos.

\subsection{Cooperação e performance permitidos pelas aprendizagens organizacionais}

A criação, na instalação $\mathrm{n}^{\circ} 2$, das funções de ITEM do palco TEM ou das reuniões de análise ad hoc não provêm nem do acaso nem de decisões unívocas de dirigentes 
optando a priori pelas soluções mais eficazes. Estas criações resultam de um longo processo de experimentação que permitiu aprendizagens múltiplas por permutas e capitalização de conhecimentos. Assim, o projecto TEM englobava, durante dois anos, dois engenheiros da condução para elaborar a engenharia dos dossiers de problemas e três coordenadores dos serviços de manutenção com vista a animar o projecto TEM. Mas os engenheiros da condução e os coordenadores não conseguiam fazer convergir os seus pontos de vista, confundiam as suas responsabilidades ou podiam reivindicar um poder decisório sobre o planeamento sem dispor necessariamente das competências técnicas adequadas. Em alguns meses, o director e o subdirector de produção, os actuais chefes do projecto TEM e dos serviços de condução, chegam concomitantemente doutros sítios. Dão-se rapidamente conta que as coordenações entre as equipas de turno e extra turno da condução e o projecto TEM apresentam dificuldades diversas. Criam vários grupos de trabalho. 0 primeiro associa os quatro actores mencionados mais os Chefes de exploração, os chefes de exploração delegados de turno e os chefes adjuntos do serviço de manutenção. Este grupo de trabalho permitiu, nomeadamente, modificar o circuito de preparação dos dossiers de intervenção e a repartição de responsabilidades entre chefes de exploração e chefes de exploração delegados. 0 chefe do projecto TEM que acabava de exercer essa função numa outra instalação, propôs as funções de ITEM em tempo real e de ITEM em tempo diferido, ensaiados numa outra instalação, bem como diversas reflexões sobre a organização do planeamento e da preparação. 0 segundo grupo de trabalho reunia os pilotos dos ofícios, os planificadores e os preparadores. Cada uma destas funções exprimia o que esperava das outras para melhorar a qualidade do seu trabalho clarificando ao mesmo tempo as responsabilidades das actividades. A partir de 2008 foi criado o ofício de ITEM e em Setembro de 2009 os dois serviços de condução fundiram-se. O chefe do projecto TEM passou assim de uma função de director de equipa à de adjunto do chefe de serviço de condução, o que lhe permitiu adquirir um acréscimo de legitimidade para fazer aceitar as suas decisões junto dos ofícios de manutenção e ao mesmo tempo consagrar-se inteiramente à direcção do projecto TEM.

50 A organização mais realizadora do projecto TEM na instalação no 2 e a melhoria da interacção entre as equipas de condução resultam assim de um processo longo e evolutivo pontuado por experiências que são outros tantos momentos de aprendizagem por tentativa e erro. Os resultados das experimentações permitiram aos protagonistas determinar as organizações que não lhes convinham para evoluir para formas mais satisfatórias. Estas evoluções representam as aprendizagens organizacionais: " consideradas como um fenómeno colectivo de aquisição, de elaboração e de deteç̧ão de conhecimentos que modificam as situações da empresa para melhorar a gestão » (Koenig, 1994). As aprendizagens organizacionais podem ser favorecidas pela produção ou a capitalização de novos conhecimentos eficazes. Os conhecimentos podem ser trazidos por novos empregados que se integram na empresa ou produzidos graças a estruturas descentralizadas como os grupos de projecto (Charue, 1994; Midler, 1993). $\mathrm{Na}$ instalação $\mathrm{n}^{\circ} 2$ foram produzidos novos conhecimentos eficazes por grupos de trabalho que são estruturas descentralizadas. Elas foram também trazidas por novos actores que tinham participado em experiências noutras instalações. A gestão do projecto TEM foi modificada de modo colectivo, naquela instalação, graças à criação $\mathrm{e}$ importação de novos conhecimentos e reflexões. 


\section{Para concluir}

51 O desafio desta contribuição foi o de aprofundar a compreensão do funcionamento normal de uma organização de risco e mais precisamente detalhar a construção da sua fiabilidade graças a uma análise das relações de coordenação e de cooperação entre serviços e equipas. A análise destas relações é essencial numa indústria de risco. Mais do que qualquer outra organização encontra-se confrontada com uma contradição essencial : 1) dever especializar e segmentar os ofícios enquanto se fazem funcionar a ritmos diferentes para fazer face à complexidade técnica das actividades ; 2 ) interligar $\mathrm{e}$ coordenar o conjunto dos ofícios para recriar uma fiabilidade e uma performance do conjunto. Desafio essencial, a coordenação de espaços e tempos profissionais internos diferenciados assenta tradicional e funcionalmente, num CNPE, na criação de planeamentos colectivos e em dossiers das intervenções. Ora estes documentos e regras prescritas apresentam sempre lacunas ao prever o trabalho real, a fortiori num contexto tão complexo e mutável como a exploração nuclear. Perturbados por prioridades profissionais divergentes e temporalidades distintas das actividades de trabalho compreendidas entre quadros temporais e meios temporais (Grossin, 1996), estes documentos apresentam maiores dificuldades para serem completados quando os espaços profissionais nunca se encontram. A organização do trabalho e as profissões cindem-se com efeito em segmentos quando as actividades, os métodos e as tecnologias se diferenciam (Strauss, 1992) ou quando as profissões colocam à margem membros de cujas capacidades, para cumprir actividades de maior risco, elas duvidam.

Se a articulação dos espaços profissionais não pode assentar exclusivamente em documentos (planeamentos, dossiers de intervenções), é facilitada graças à criação de funções e de organizações específicas que se centram em actores reconhecidos como tecnicamente competentes. Envolvendo-se estes actores confrontam-se com outrem para completar as suas abordagens e desencadear conhecimentos variados sobre as suas actividades. Essa implicação e as suas competências incrementam a confiança dos membros das equipas de condução de turno, atenuam os controlos e a tentação para reportar a actividade a uma outra equipa. No quotidiano, a fiabilidade aumenta assim ao passar de uma coordenação por documentos a uma cooperação que assenta na doação e retribuição de conhecimentos e serviços. Estas permutas entre indivíduos e serviços são decerto facilitadas por certas funções (ITEM) e espaços (a elas) dedicados (palco TEM por exemplo), mas a história da instalação no 2 mostra-nos que a sua criação não resulta da simples duplicação de organizações ou de tecnologias importadas. Teria sido assim tentador limitar os nossos conselhos, à instalação $\mathrm{n}^{\circ}$ 1, à proposta de integrar no seu seio grande número dos dispositivos eficazes da instalação $\mathrm{n}^{\circ} 2$ (criação das funções dos ITEM's em tempo real e diferido, complementaridade entre os seus perfis, escolha das pessoas mais competentes, reforço do número de preparadores, espaços de deliberação e palco TEM ...). Todavia, na instalação $n^{\circ}$ 2, a criação destas funções e espaços foi permitida graças a um longo processo de inovação que acolheu diversas experimentações. Esses ensaios permitiram acumular conhecimentos a fim de criar as soluções endógenas mais adequadas. Assim, a melhoria da fiabilidade e da performance destas organizações de risco parecem residir menos na duplicação de dispositivos ensaiados noutros lugares do que na sua capacidade de inovar constantemente para inventar soluções organizacionais e sociais endógenas que aproximam e articulam temporalidades e espaços dissociados. Este processo de 
inovação assenta na experimentação aliada a uma importação e transformação de novos conhecimentos para desembocar em novas soluções graças a deliberações colectivas.

\section{Glossário}

AAR - Paragem automática do reactor

AIEA - Agência Internacional para a Energia Atómica

CE - Chefe de Exploração

CED - Chefe de Exploração Delegado

CNPE - Centro Nuclear de Produção de Electricidade

ECQ - Equipas de Condução de Turno

INSAG - Grupo Internacional de Aconselhamento da Segurança Nuclear

(International Nuclear Safety Advisory Group)

ITEF - Engenheiro de Unidade em Funcionamento - Ingenieur Tranche En Fonctionnement

\section{BIBLIOGRAFIA}

Alter, N. (2009), Donner et prendre. Paris : La Découverte.

Arendt, H. (1958/1994). Condition de l'homme moderne. Paris : Agora.

Barthe, B., \& Queinnec, Y. (1999). Terminologie et perspectives d'analyse du travail collectif en ergonomie. L'Année psychologique, 99, (4), 663-686.

Bourrier, M. (1999). Le nucléaire à l'épreuve de l'organisation. Paris : P.U.F, Collection Le travail humain.

Bourrier, M. (éds). (2001). Organiser la fiabilité. Paris : L'Harmattan, Collection risques collectifs et situations de crise.

Charue, F., \& Midler, C. (1994). Apprentissage organisationnel et maîtrise des technologies nouvelles. Revue Française de Gestion, 97.

Chateauraynaud, F. (1997). Vigilance et transformation. Réseaux, 85.

Cordonnier, L. (1994). Coopération et réciprocité. Paris : P.U.F.

Crozier, M. (1963). Le phénomène bureaucratique. Paris : Le seuil.

Davoudian, K., \& Apostolakis, G. (1994). Incorporating organizational factors into risk assessment through the analysis of work processes. Reliability Engineering and System Safety, 45, 85-105.

Duclos, D. (1987). La construction sociale du risque : le cas des ouvriers de la chimie face aux dangers industriels. Revue Française de Sociologie, XXVIII, 17-42. 
Evans-Pritchard, E.E. (1937/1994). Les nuer. Paris : Gallimard.

Grossin, W. (1996). Pour une science des temps. Paris : Octarès.

Guillaume, O., \& Labarthe, J. P. (2008). Conception d'une nouvelle organisation du travail et coopération entre ergonomes et sociologues. Actes $d u 43^{\circ}$ Congrès de SELF, France.

Harvey, J., Hedos, G., Bolam, H., Cox, M. A. A., Kennedy, J. N. P., \& Gregory, D. T. (2002). Analysis of a safety culture in a highly regulated environment. Work and stress, Vol 16, (1), 18-36.

Hermet G. (1998). Quel espace de sens pour l'Europe ? In Z. Laïdi (éd), Géopolitique du sens. Paris : Desclée de Brouwer.

Jobert, G. (2005). Engagement subjectif et reconnaissance au travail dans les systèmes techniques. Revue Internationale de Psychosociologie, vol. XI, (1), 67-95.

Koenig, G. (1994). L’apprentissage organisationnel : repérage des lieux. Revue Française de Gestion, 97, Janvier - février.

Laïdi, Z. (éd). (1998). Géopolitique du sens. Paris : Desclée de Brouwer.

La Porte, T. (2002). Fiabilité et légitimité soutenable. In M. Bourrier (éds), Organiser la fiabilité.

L'Harmattan, Collection Risques collectifs et situations de crise.

Mauss, M. (1950/2004). Sociologie et anthropologie. Paris : PUF.

Merton, R. K. (1965). Eléments de théorie et de méthode scientifique. Paris : Plon.

Midler, C. (1993). L'auto qui n'existait pas. Management des projets et transformation de l'entreprise, Paris : Interéditions.

Osty, F. (2002). Le désir de métier. P.U.R. : Rennes.

Perrow, C. (1984). Normal accidents. New York: Basic Books.

Pidgeon, N. (1998). Safety culture: key theoretical issues. Work and stress, 1998, vol. 12, (3), 202-216.

Rochlin, Gene I. (2001). Les organisations à "haute fiabilité" : bilan et perspectives de recherche. In Bourrier, M. (éds), Organiser la fiabilité, Paris, L'Harmattan, Collection risques collectifs et situations de crise.

Simmel, G. (1999). Sociologie. Paris : PUF.

Sorokin, P. A. (1964). Sociocultural causality space, time: a study of referential principles of sociology and social science. New York: Russell \& Russell.

Sue, R. (1994). Temps et ordre social. Paris : PUF.

Saglio J. (2001). Souplesse du quotidien et rigidité dans la crise : l'organisation du travail sur un bateau de guerre. In M. Bourrier (éds), Organiser la fiabilité. Paris : L'Harmattan, collection Risques collectifs et situations de crise.

Strauss, A. (1961/1992). La trame de la négociation. Paris : L’Harmattan.

De Terssac, G. (1992). Autonomie dans le travail. Paris : P.U.F.

Zonabend, F. (1989). La presqu'île au nucléaire. Paris : Odile Jacob.

\section{NOTAS}

1. NT - ECQ vem de "equipes de conduite en quart" que foi traduzido por Equipas de Turno. 
2. Os termos entre parêntesis encontram-se num glossário localizado no final do artigo.

3. Tomando de empréstimo as categorias de H. Arendt (1958/1994), G. Jobert (op. cit. p. 71) mostra que as suas actividades não lhes permitiam nem aceder à de obra nem à de acção. 0 trabalho designa a actividade submetida à necessidade vital. A obra fornece um mundo de objectos duráveis diferentes do meio natural. A acção permite à identidade pessoal de se realizar. Exige a existência de um domínio público onde cada um possa, pela palavra, tornar visível e afirmar a sua grandeza.

4. Quando em funcionamento normal, os membros dos navios de guerra não respeitam todas as ins-truções, seleccionam as suas actividades, recompõem-nas parcialmente ou negoceiam as situações a fim de não bloquear a organização. Os procedimentos nem sempre são de facto adaptados e a sua modificação seria muito demorada. Em contrapartida, quando em combate, a organização retoma a rigidez : os regulamentos são aplicados à letra, as decisões hierárquicas não são discutidas nem pos-tas em causa.

5. Quando em funcionamento normal, os membros dos navios de guerra não respeitam todas as instruções, seleccionam as suas actividades, recompõem-nas parcialmente ou negoceiam as situações a fim de não bloquear a organização. Os procedi-mentos nem sempre são de facto adaptados e a sua modifica-ção seria muito demorada. Em contrapartida, quando em combate, a organização retoma a rigidez: os regulamentos são aplicados à letra, as decisões hierárquicas não são discutidas nem postas em causa.

6. Pode pensar-se, nomeadamente nos trabalhos de D. Duclos (1987) ou de F. Zonabend (1987) que trazem à luz identidades e culturas profissionais variadas face aos riscos e à segurança.

7. Na instalação no 1 a quase totalidade dos agentes dos serviços de manutenção trabalha $32 \mathrm{~h}$ em quatro dias por semana. Mesmo assim existem ainda equipas adstritas à manutenção que podem intervir fora dos seus horários de trabalho em caso de incidentes importantes.

8. O dossier de intervenção pode integrar a gama de intervenção, o plano de qualidade, uma resenha das peças separadas, a análise do risco e a Ficha de Simples Requalificação. O dossier enuncia igualmente os pontos-chave da intervenção e propõe uma bula de instruções, quer dizer, a representação dos circuitos a tornar inoperantes para evitar que o operador se fira.

9. Nomeadamente os acidentes de Bhopal e de Tchernobyl nos anos 1980.

10. Significa repor em funcionamento uma parte da instalação que estava desligada para se proceder a uma intervenção

\section{RESUMOS}

Esta contribuição encara as organizações de risco como a articulação de múltiplos espaços profissionais com temporalidades diferenciadas. Sob o risco de verem as suas fiabilidade e produtividade reduzidas, a exploração das organizações produtivas deve imbricar múltiplos espaços profissionais, actividades e temporalidades, graças a planeamentos e dossiers de intervenção. Mas estes documentos podem mostrar-se insuficientes. Os planeamentos são perturbados pelo aleatório, a apreensão do risco e os tempos gerados pelas actividades profissionais variam. Os dossiers de intervenção nem sempre são suficientemente enriquecidos em virtude de espaços profissionais segmentados e quando os indivíduos têm dificuldades para se encontrarem. Baseado num estudo empírico comparativo entre duas instalações esta contribuição mostrará que a articulação dos tempos e dos espaços das organizações de risco mostra-se mais eficaz quando, à coordenação por planeamentos e dossiers de intervenção, se 
acrescenta uma cooperação entre indivíduos de reconhecida legitimidade técnica. Eles centralizam e redistribuem as informações em tempo real, admitindo também encontros cara-acara. Visto de modo mais lato, a fiabilidade destas organizações aumenta quando se dotam de funções, de espaços ou de tecnologias adequados graças a um processo longo de inovação e de aprendizagens.

Esta contribución aborda las organizaciones riesgosas como una articulación de múltiples espacios profesionales con temporalidades diferenciadas. Temiendo ver su fiabilidad y su productividad reducidas, la explotación de las organizaciones productivas debe articular múltiples espacios profesionales, actividades y temporalidades mediante la planificación y programación del trabajo. Pero dichas programación y planificación pueden revelarse insuficientes. La programación puede ser alterada por les gajes del oficio, la aprensión al riesgo y los tiempos generados por las variaciones de las actividades profesionales. Ante la segmentación de los espacios profesionales y los problemas que tienen los individuos para encontrarse, los programas de trabajo no son lo suficientemente alimentados y la planificación falla. Basada en un estudio empírico y comparativo de dos sitios nucleares, dicho artículo muestra que la articulación de los tiempos y de los espacios de las organizaciones con riesgos aparece más eficaz cuando a la coordinación de la planificación y la programación del trabajo se le adjunta una cooperación entre individuos reconocidos desde el punto de vista técnico. Estos centralizan y redistribuyen en tiempo real las informaciones, al mismo tiempo que aceptan los encuentros cara a cara. De manera general, la fiabilidad de dichas organizaciones aumenta cuando estas se dotan de funciones, de espacios o de tecnologías adecuadas mediante un proceso largo de innovación y de aprendizaje.

Cette contribution envisage les organisations à risque comme l'articulation de multiples espaces professionnels aux temporalités différenciées. Au risque sinon de voir leur fiabilité et leur productivité réduites, l'exploitation des organisations productives doit imbriquer de multiples espaces professionnels, activités et temporalités grâce à des plannings et des dossiers d'intervention. Mais ces documents peuvent s'avérer insuffisants. Les plannings sont perturbés par les aléas, l'appréhension du risque et les temps générés par les activités professionnelles varient. Les dossiers d'intervention ne sont pas toujours suffisamment enrichis en raison d'espaces professionnels segmentés et quand les individus éprouvent des difficultés à se rencontrer. Basée sur une étude empirique comparative entre deux sites, cette contribution montrera que l'articulation des temps et des espaces des organisations à risque s'avère plus efficace quand à la coordination par des plannings et des dossiers d'intervention, s'adjoint une coopération effectuée par des individus reconnus légitimes techniquement. Ils centralisent et redistribuent en temps réel les informations tout en acceptant les rencontres en face-à-face. Plus largement, la fiabilité de ces organisations s'accroît quand elles se dotent de fonctions, d'espaces ou de technologies adéquates grâce à un processus long d'innovation et d'apprentissages.

This contribution considers risky organizations as the link between multiple professional spaces with different temporalities. Risking to see their reliability and their productivity otherwise reduced, the exploitation of the productive organizations has to interlock multiple professional spaces, activities and temporalities thanks to schedules and intervention files. But these documents can turn out to be inadequate. Hazards, the apprehension of risk and the professional activities' length interfere with the schedules. Intervention files are not always enhanced enough because of segmented professional spaces and the individual difficulties to meet each others. Based on a comparative empirical study between two sites in the nuclear area, this contribution will show that the junction of time and space in risky organizations turns out more effective when a cooperation made by justifiable recognized individuals technically is appointed to the coordination by schedules and files of intervention. They centralize and redistribute in real-time 
the information while accepting the meetings. To a larger extent speaking, the reliability of these organizations increases when they are equipped with positions, with spaces or with adequate technologies thanks to a long process of innovation and learning.

\section{ÍNDICE}

Keywords: technical systems operating, time, spaces, coordination, cooperation

Palavras-chave: exploração de sistemas sócio técnicos ; tempo ; espaços ; coordenação ; cooperação

Palabras claves: explotación de sistemas socio-técnicos, tiempo, espacios, coordinación, cooperación

Mots-clés: exploitation des systèmes socio-techniques, temps, espaces, coordination, coopération

\section{AUTOR}

\section{OLIVIER GUILLAUME}

Chercheur Groupe Facteurs Humains EDF R\&D \& Membre-Partenaire du LISE/CNAM/CNRS, EDF R\&D, Management des Risques Industriels, 1, Av. Général de Gaulle, 92140 Clamart - France oh.guillaume@free.fr 